The International Conference on Emerging Trends in Engineering and Technology (IConETech-2020)

Faculty of Engineering, The UWI, St. Augustine | June $1^{\text {st }}-5^{\text {th }}, 2020$

\title{
DELAYED PAYMENTS IMPACTS ON PLANNED CASH FLOW OF SMALL AND MEDIUM CONTRACTORS FOR A SPECIAL PURPOSE COMPANY
}

\author{
Shawn Bissoon ${ }^{1}$ and Derek Outridge ${ }^{2}$ \\ ${ }^{1,2}$ Faculty of Engineering, The University of the West Indies, Trinidad \\ ${ }^{1}$ Email: shawnbissoon@ hotmail.com \\ ${ }^{2}$ Email: derek.outridge@sta.uwi.edu
}

\begin{abstract}
The FIDIC suite standard forms of contracts used for executing projects in Special Purpose Companies contain contractual and administrative provisions regarding payments. However, payment delays continue to plague the construction industry to date. Delay payments generally have an adverse effect on a company's cash flow, leading to extensions on overdraft facilities, ultimately increasing their borrowing. Late payment of commercial debt adversely affects the liquidity of contracting companies sometimes leading to insolvency.
\end{abstract}

This study examined the impact of the contractual payment period and payment process on the cash flow of contractors executing projects for the Special Purpose Company (SPC) E. The sample population chosen for this research consisted of 100 small and medium contractors within the SPC-E to illustrate the varying effects of the payment delays on the contractors mostly affected. A review of previously published literature along with a questionnaire survey distributed, determined the objectives of the paper. Statistical analysis using IBM SPSS software further analyzed the data collected using Cumulative Means, Relative Importance Index, Spearman's Rank Correlation and Analysis of Variance (ANOVA) to test the hypothesis.

The complicated bureaucratic payment process utilized by the SPC-E resulted in the cascading adverse effects on the contractor's cash flow. The findings also indicated that there has been no significant improvement to the delayed payment issue over the past decade. The implementation of Prompt payment legislation or statutory adjudication is recommended to ensure the sustainability of small and medium contractors.

Keywords: Delayed payments, Planned cash flow, Contract payment periods, Prompt payment legislation.

https://doi.org/10.47412/XCDI8337

\section{Introduction}

Payment delays remain one of the fundamental problems still facing the Trinidad \& Tobago (T\&T) construction industry during 2010 to 2019, which is further compounded by falling oil prices. Project success depends on well-organized and timely payments [1]. Payments are the crucial lifeblood of any project facilitating the, preliminaries, materials, labour, plant, subcontractors' 
work and general overheads during the progress of the work [11]. The negative net cash flow resulting from delayed payments leads to insolvency in many companies [1].

Minimizing payment delays on any project is of major importance. The link between cash flow and the effectiveness of the payment mechanism used to facilitate timely payments is fundamental to the survival of the contractor [16]. In 2016 the past president of the Trinidad and Tobago Contractors Association (TTCA), stated, "Contractors are owed some $\$ 2$ billion by Government and due to no money coming in from jobs completed, they have no choice but to send home employees because they could not be kept on the payroll" [15]. Elias (2016) suggested using government bonds to pay off the $\$ 2$ billion debt owed to contractors. He also indicated that even though the government is a major client to the construction industry, contractors must also be mindful of the four-year statute of limitation and take the necessary legal steps to protect their interest where delayed payments are concerned.

This study focused on the effects that the SPC-E's payment system had on the planned cash flow for small and medium contractors during the period 2010 to 2019. The research focused on these categories of contractors as they were mostly affected by the delayed payments over the last decade. It involved a detailed review of the payment system utilized by SPC-E based on the contractual agreement and a review of the bureaucratic payment process utilized by its client ministry during the execution of projects. Additionally, the study involved a comprehensive literature review on scholarly articles that dealt with delayed payments to contractors. The analysis undertaken for this study was similar to that of Charles-Ragoo (2015), utilizing the relative importance index method to investigate the unfair payment practices for the construction industry of T\&T. The research highlighted the cause of delay payments which act as a catalyst for policy makers to implement measures to curb the crippling effect to the industry. It reiterated the need to implement the recommendations suggested in the Uff and Thornhill (2010) Report to curb the effects of delayed payments given that, to date, the issue continues to plague the construction sector of $\mathrm{T} \& \mathrm{~T}$.

\section{Literature Review}

The culture of delayed payments on government contracts has adversely affected the cash flow of contractors within the construction industry leading to incomplete projects and bankruptcy in severe cases. The review of the literature indicated the following reasons for the delayed payments on government contracts:

- Client's poor financial and business management

- Client withholding payment

- Contractor's invalid claim

- Delay in valuation and certification

- Inaccuracy of evaluation

- Insufficiency of documentation

- Deliberate manipulation of procurement practices 
- Inadequate legislation to curb delayed payment

- Commencing projects without funding availability

\subsection{Payment Conditions}

The number one concern for contractors is the cash flow on a project indicating that "cash is king" [16]. Late payments can create cash flow problems and unnecessary financial burdens on contractors [5]. As stated by Munaaim, Danuri \& Abdul-Rahman (2007), the most appropriate solutions for late and non-payments faced by local contractors include a right to regular periodic payments, a defined timeframe for payments and an effective dispute resolution process.

Standard forms of contracts seek to curb the effect of delayed payments experienced by contractors in the construction industry [5]. Ang Su Sin (2006) stated that most standard forms of contract contain clauses that govern all aspects of payments under the contract. The following FIDIC 1999 suite of contracts governed projects executed by SPC-E:

- FIDIC First Edition 1999 - Short Form of Contract (Green Book) used for Repair and Maintenance projects, which are less technical with aggressive schedules of completion.

- FIDIC First Edition 1999 - Conditions of Contract for Construction (Red Book) used for projects that have been designed by the client and given to the contractor to construct.

- FIDIC First Edition 1999 - Conditions of Contract for Plant and Design Build (Yellow Book) used for projects that require the contractor to design and construct the project based on a client brief.

\subsection{Review of the Contractual Payment Period and Payment Process}

The success of any construction project depends on the selected payment system to the project's uniqueness and client's requirements [16]. A detailed review into the different types of contractual payment periods along with internal payment information detailing the actual payment of invoices and Interim Payment Certificate (IPCs) were examined for projects executed by SPC-E.

The Particular Conditions utilized by SPC-E for projects executed under the FIDIC Red and Yellow book did not make changes to the payment duration stated in the standard FIDIC Contracts, nor any adjustment to the clauses dealing with Delayed payments. Amendments made for projects executed under the FIDIC Short Form of Contract allowed for payment upon the successful completion of the works, removing the sub-clause dealing with interim payments. Review of internal documents indicated that projects governed by the FIDIC Red and Yellow book experienced payment delays to Interim Payment Certificates (IPC's) resulting in contractual disputes and claims for extension of time on various projects. The general conditions of contract did not factor in the time taken by the bureaucratic approval process for making payments, neither was there any particular condition of contract making provision for such additional time. The bureaucratic approval process, of its client ministry, takes an additional 16 main steps for processing payments to contractors for works certified by the SPC-E, resulting in significant delays in payments to contractors. 


\subsection{The Continuing Trend}

Review of internal payment tracking systems indicated that payment delays took an average 2 to 6 months and in some extreme cases years before being resolved. The SPC-E attempted to avoid the long bureaucratic payment system of its line ministry by directly submitting invoices to the Ministry of Finance to expedite payments but met challenges resulting from another system of verification before making any payments.

Chin (2012) stated that over \$500 million Trinidad and Tobago Dollars remained unpaid from various SPCs and the interest accrued on the payments received from 2010 absorbed any profits for the contractor. Research done by Braithwaite (2010), Allaham (2010), Felmine (2013) and Ramdass (2016) showed the impact developing from delayed payments over the years. These various articles all indicate that many contractors go into receivership and the ones that continue to work are not paid on time. Dowse (2013) stated that late payments decimates cash flow and forces the failure of many businesses. This research shows the need to address the issue of the delay payment culture continued during the harsh economic period over the past decade to curb the adverse effects of the productivity of the Country's construction industry.

\section{Methodology}

The study investigated the contractual payment period established by the general conditions for the various contracts governing projects executed by the SPC-E along with the payment process utilized by the parent ministry. The following research questions were developed in executing the research paper:

- How does the contractual payment period affect the cash flow of small and medium contractors executing jobs for SPC-E?

- What is the average waiting time for payments to contractors executing jobs for SPC-E?

- How does delay payments affect the contractor's cash flow?

\subsection{Research Design}

The study adopted the following modified approach of the paper entitled "Fair Payment Security Strategy for the Trinidad and Tobago Construction Industry" done by Charles-Ragoo (2015), due to the similarity of the content:

- Phase 1 - Secondary Data Collection in the form of Desktop study

- Phase 2 - Pilot Survey

- $\quad$ Phase 3 - Primary Data Collection in the form of Questionnaire Survey

The mixed method approach, integrating both quantitative and qualitative research methods facilitated a comprehensive understanding of the study [8]. The research paper showed the need to implement the recommendations suggested by Uff and Thornhill (2010) report to address the payment problem experienced by contractors executing projects for the SPC-E. It evaluated the link between the contractual payment period and the actual payment process utilized by SPC-E. The methodology presented a structured approach to test the following hypothesis:

Delayed payments adversely affect the cash flow of Small and Medium Contractors in SPCE. 


\subsubsection{Desktop study}

A desktop study was conducted in order to:

- Gather and analyze existing information relating to the topic of investigation.

- Obtain a further guide on executing the study based on the methods employed previously by researchers and their results.

\subsubsection{Validity Testing}

In testing the validity of the research design, a pilot test was conducted with experts in the field. Based on their knowledge and expertise, a critic of the research design was completed and returned to the researcher with comments and suggestions. The questionnaire survey was amended and then distributed to the selected sample.

\subsubsection{Questionnaire Survey}

The questionnaire survey gathered the following information after being tailored utilizing the recommendations of the Pilot test:

- The significance of the contract payment period on cash flow.

- The effect of the payment process employed on the contractual payment period.

- The main effects of delayed payments to the cash flow of the sample population.

- The preferred options available to curb the adverse effects of the delayed payment.

- The preferred recommendations made to mitigate the effects on the cash flow of the contractors.

\subsubsection{Reliability Test}

The Cronbach's coefficient alpha test in SPSS determined the reliability of the questionnaire survey, which gave the average correlation among all the items that make up the scale [14]. The rule governing the Cronbach's coefficient alpha stated that the closer the value is to 1, the greater the consistency of the items [14]. The results proved the reliability of the research method.

Case Processing Summary

\begin{tabular}{|c|c|c|}
\hline & $\mathrm{N}$ & $\%$ \\
\hline Cases Valid $^{\mathrm{a}}$ & 80 & 100.0 \\
\hline Excluded $^{\mathrm{a}}$ & 0 & 0 \\
\hline Total & 80 & 100.0 \\
\hline
\end{tabular}

\section{Reliability Statistics}

\begin{tabular}{|c|c|}
\hline $\begin{array}{c}\text { Cronbach's } \\
\text { Alpha }\end{array}$ & $\begin{array}{c}\text { No of } \\
\text { items }\end{array}$ \\
\hline 0.957 & 28 \\
\hline
\end{tabular}

${ }^{\mathrm{a}}$ Listwise deletion based on all variables in the procedure

\section{Sampling Design}

The questionnaires were randomly administered to 100 Small and Medium contractors registered with SPC-E that executed projects during the period 2010 - 2019 to be returned anonymously. The use of the company's internal registry facilitated the random selection of the sample population for this research. This allowed for a wider range of different knowledge, experiences and skill sets to be captured. Allowing for more depth and credibility of the results in an unbiased manner. 
In determining the sample size for this research, the Kish (1965) formula was applied, at a confidence level of 95\% (Assaf \& Al-Hejji, 2006) based on the sample population of 100 contractors:

$$
\mathrm{n}=\frac{n^{1}}{\left[1+\left(\frac{n^{1}}{N}\right)\right]}
$$

Where: $\mathrm{N}=$ total population $=100$

$\mathrm{n}^{1}=$ a sample size from an infinite population $=\mathrm{s}^{2} / \mathrm{v}^{2}$

$\mathrm{s}^{2}=$ variance of the population $=(0.5)^{2}$

A variance of $50 \%$ was selected for this research as to allow and account for maximum variance possible

$$
\begin{aligned}
\mathrm{v}^{2}=\text { standard error } & =(0.05)^{2} \\
& \therefore n=\frac{n^{1}}{1+n^{1} / N}=\frac{100}{1+100 / 100}=50
\end{aligned}
$$

Using a non-responsive rate of $12 \%$ based on the acceptable rate of 5 to 15 percent [3]

Allowable Non-responsive outcomes $=\frac{12}{100} * 50=6$

The results indicated that a minimum of 56 total contractors must respond to make the study viable. The questionnaire was emailed directly to each respondent utilizing the SPC-E database which resulted in 80 responses making the research viable.

\subsection{Data Analysis Procedures}

Descriptive statistical analysis utilized the statistical software Statistical Packages for Social Sciences (IBM SPSS) to analyse the effects of the delayed payment to contractors and the available practices used to curb these effects. It also analyzed the effects of the delayed payment to contractors against the suggested recommendations to test the hypothesis of the research. Descriptive statistical analysis includes determining mean scores, variances and percentage frequencies as measures of central tendency [14].

The analysis techniques employed were the Relative Importance Index (RII), the Frequency Index, the Severity Index, Spearman's Rank Correlation and the Analysis of Variance (ANOVA). The 5point Likert scale ranging from "strongly disagree" to "strongly agree" provided the options available for the respondents to rank the significance of each variable. The analysis compared the effects to the Project Cash Flow (dependent variable) by the three main independent variables; payment procedure of the line ministry to SPC-E, the payment procedure at the SPC-E and the contractual payment period.

\section{Hypothesis Testing}

One-Way Analysis of Variance (ANOVA) tested the research Hypothesis to compare the accuracy of the data. The following were developed in relation to ANOVA: 
- Ho or Null Hypothesis stated that there is no significant difference between the size of contractors executing projects for SPC-E and the effects of the Delayed payments on the cash flow.

- $\mathbf{H}_{1}$ or Alternative Hypothesis stated that there is significant difference between the size of contractors executing projects for SPC-E and the effects of the Delayed payments on the cash flow.

The One-Way ANOVA provided statistical evidence to determine the significant differences between the means of the variables as obtained from the questionnaire survey. In relation to ANOVA, the rule states if the significance $\mathrm{P}$ (sig. value) $>0.05$ then $\mathrm{H}_{0}$ is true for $\mathrm{F}$ close to 1, i.e. if $\mathrm{H}_{0}$ is true $\mathrm{H}_{1}$ will be rejected (Pallant, SPSS SURVIVAL MANUAL, A step by step guide to data analysis using IBM SPSS 5th Edition, 2013). With the use of ANOVA the following assumptions were utilized:

- The expected values of errors are zero

- The variances of all errors are equal to each other

- The errors are independent

- The variables are normally distributed

\section{Results/Discussion}

The first two objectives were obtained by discussing the different contracts utilized by the SPC-E when executing projects within the 2010 to 2019 study period. A review of the particular conditions of the amended contracts determined the effects of the actual payment period on the proposed cash flow for the contractors. The analysis of the primary data collected indicated the effects delayed payments had on the contractor's cash flow and recommended the most suitable options available to curb the adverse effects of delayed payments.

\subsection{Analysis of the Effects of Delayed Payments to the Contractors - RII}

The analysis of the results as indicated in Table 1, revealed that small and medium contractors are affected similarly by delayed payments. The results proved to be similar for previous research done by Charles-Ragoo (2015) which indicated that there has been no significant improvement of the situation over the past decade.

Table 1 Ranking of the effects of delay payments on cash flow

\begin{tabular}{|c|c|c|c|c|}
\hline $\begin{array}{c}\text { Late Payment Effect } \\
\text { on Contractors }\end{array}$ & $\begin{array}{c}\text { RII } \\
\text { Small } \\
\text { Contractors }\end{array}$ & $\begin{array}{c}\text { Rank } \\
\text { Small } \\
\text { Contractors }\end{array}$ & $\begin{array}{c}\text { RII } \\
\text { Medium } \\
\text { Contractors }\end{array}$ & $\begin{array}{c}\text { Rank } \\
\text { Medium } \\
\text { Contractors }\end{array}$ \\
\hline Reduces Business Profitability & 0.937142857 & 1 & 0.9272727 & 1 \\
\hline Increases Late Paying to Suppliers & 0.857142857 & 5 & 0.9272727 & 1 \\
\hline Difficulty to Procure Material \& Services & 0.874285714 & 3 & 0.8818182 & 3 \\
\hline Increases Construction Cost & 0.862857143 & 4 & 0.8909091 & 2 \\
\hline
\end{tabular}




\begin{tabular}{|c|c|c|c|c|}
\hline Force to Borrow Additional Funding & 0.88 & 2 & 0.8545455 & 4 \\
\hline Leads to Suspension of Works & 0.794285714 & 7 & 0.8454545 & 5 \\
\hline Downsizing Company & 0.794285714 & 7 & 0.7909091 & 8 \\
\hline Abandonment of Projects & 0.765714286 & 9 & 0.7454545 & 10 \\
\hline Extension of Project Completion Date & 0.834285714 & 6 & 0.8545455 & 4 \\
\hline Adversely affects Company's Reputation & 0.765714286 & 9 & 0.8 & 7 \\
\hline Result in Litigation / Arbitration & 0.737142857 & 11 & 0.8272727 & 6 \\
\hline Difficult to Tender for New Projects & 0.782857143 & 8 & 0.8 & 7 \\
\hline Bankruptcy or Liquidation & 0.754285714 & 10 & 0.7727273 & 9 \\
\hline No impact & 0.365714286 & 12 & 0.3363636 & 11 \\
\hline
\end{tabular}

\subsection{Analysis of the Options Available to Curb Delayed Payment Effects to the Contractors - RII}

The results displayed in Table 2, show that contractors considered Mandatory Payment Terms, Advance Payments, Defined payment periods, Litigation and suspending works as the most viable options available to curb the effects of delayed payments. The results presented confirms the findings of previous research done by Charles-Ragoo (2015). Further analysis of the findings revealed that the contractors considered similar options as most viable but varied their importance based on their financial capacity.

Table 2 Ranking of the options available to curb the effects of delay payments on cash flow

\begin{tabular}{|c|c|c|c|c|}
\hline $\begin{array}{c}\text { Options Available to Curb Late } \\
\text { payment effects } \\
\text { on Contractors }\end{array}$ & $\begin{array}{c}\text { RII } \\
\text { Small } \\
\text { Contractors }\end{array}$ & $\begin{array}{c}\text { Rank } \\
\text { Small } \\
\text { Contractors }\end{array}$ & $\begin{array}{c}\text { RII } \\
\text { Medium } \\
\text { Contractors }\end{array}$ & $\begin{array}{c}\text { Rank } \\
\text { Medium } \\
\text { Contractors }\end{array}$ \\
\hline Increased tender/bid estimates & 0.7714286 & 5 & 0.7545455 & 6 \\
\hline Decline to submit bids & 0.7428571 & 7 & 0.7454545 & 7 \\
\hline Reduce Work program & 0.7657143 & 6 & 0.7454545 & 7 \\
\hline Increase Debt Financing & 0.8171429 & 2 & 0.7727273 & 5 \\
\hline Suspend Work & 0.7714286 & 5 & 0.8 & 4 \\
\hline Reduce material quality & 0.6171429 & 8 & 0.5818182 & 8 \\
\hline Define Payment Period & 0.7714286 & 5 & 0.8272727 & 2 \\
\hline
\end{tabular}




\begin{tabular}{|c|c|c|c|c|}
\hline $\begin{array}{c}\text { Demand Mobilization fees prior to } \\
\text { work }\end{array}$ & 0.8057143 & 3 & 0.8363636 & 1 \\
\hline Mandatory payment terms & 0.8285714 & 1 & 0.8363636 & 1 \\
\hline Increase use of Litigation & 0.7885714 & 4 & 0.8090909 & 3 \\
\hline
\end{tabular}

\subsection{Analysis of the Suggested Recommendations to Counter Delayed Payment to the Contractors - Relative Importance Index}

The results indicated in Table 3, show that contractors considered standardization of contracts adopting international standards as the most viable recommendation to curb the effects of delayed payments. Medium contractors also indicated the establishment of a specialist court as a main remedy to address the delay payment issue among contractors. Both categories of contractors agreed that Government bonds would alleviate the insurmountable debt owed. Small contractors ranked the introduction of legislation as the least favourable but medium contractor considered it as very important.

Table 3 Ranking of suggested recommendations to counter delayed payments on cash flow

\begin{tabular}{|c|c|c|c|c|}
\hline $\begin{array}{c}\text { Suggested } \\
\text { Recommendations }\end{array}$ & $\begin{array}{c}\text { RII } \\
\text { Small } \\
\text { Contractors }\end{array}$ & $\begin{array}{c}\text { Rank } \\
\text { Small } \\
\text { Contractor } \\
\text { s }\end{array}$ & $\begin{array}{c}\text { RII } \\
\text { Medium } \\
\text { Contractors }\end{array}$ & $\begin{array}{c}\text { Rank } \\
\text { Medium } \\
\text { Contractor } \\
\text { s }\end{array}$ \\
\hline $\begin{array}{c}\text { Standardization of Contracts } \\
\text { adopting UK and } \\
\text { International Standards }\end{array}$ & 0.8628571 & 1 & 0.8545455 & 1 \\
\hline $\begin{array}{c}\text { Establishment of Specialist } \\
\text { Court }\end{array}$ & 0.8228571 & 2 & 0.8545455 & 1 \\
\hline $\begin{array}{c}\text { Arbitration Act or Prompt } \\
\text { Payment Legislation }\end{array}$ & 0.8 & 4 & 0.8454545 & 2 \\
\hline Government Bonds & 0.8057143 & 3 & 0.7454545 & 3 \\
\hline
\end{tabular}

\subsection{The ANOVA Test}

The test of the hypothesis of the research paper compared the effects of the delayed payments grouped together against the value of payments outstanding using ANOVA. The results indicated that the $\left(\mathbf{H}_{0}\right)$ or the Null hypothesis was not rejected since the $\mathrm{P}$ (sig. value) $>0.05$ confirming that delayed payments adversely affected the cash flow of contractors executing projects for the SPCE over the last decade irrespective of their size as small or medium contractors. 
Table 4 - Results of the ANOVA Test on the Hypothesis.

\begin{tabular}{|c|c|c|c|c|c|}
\hline \multicolumn{7}{|c|}{ ANOVA } \\
\hline Effects of Late Payment of Invoices on Cash Flow over the \\
period $2010-2019$ \\
\hline EFFECTS & $\begin{array}{c}\text { Sum of } \\
\text { Squares }\end{array}$ & df & $\begin{array}{c}\text { Mean } \\
\text { Square }\end{array}$ & F & Sig. \\
\hline Between Groups & 6.079 & 3 & 2.026 & .816 & .489 \\
\hline Within Groups & 188.809 & 76 & 2.484 & & \\
\hline Total & 194.888 & 79 & & & \\
\hline
\end{tabular}

\section{Conclusion \& Recommendations}

The research paper assessed the impacts of delayed payments to small and medium contractors of SPC-E when executing projects over the period, 2010 to 2019. The extremely bureaucratic payment process of the line ministry to the SPC-E significantly affected the payment to contractors and must be considered to make amendments to the payment clauses within the contract. The study examined the contractual payment period along with internal payment information of the SPC-E detailing the actual payment of the Interim Payment Certificate (IPCs). After review of internal payment tracking information, the results indicated some contractors waited for a period of 2-6 months and in extreme cases years before receiving payments. Cash flow issues led to reducing business profitability, late payment impacts to the project supply chain, suspension of works and insolvency.

Propose improvements to SPC-E's contractor payment system was obtained partially from a desktop study on strategies executed globally for the construction industry inclusive of the Uff and Thornhill (2010) report and by statistical analysis of the responses obtained from the sample population in the study. The results suggested the implementation of legislation and the use of particular conditions to adjust payment clauses considering the timeframe of the bureaucratic payment system. The study highlighted standardizing contracts with international standards, enforcing laws to address the delayed payment problem and utilizing government bonds to reduce the debt owed to contractors as reasonable measure to mitigate against the delayed payment problem. Other recommendations encouraged establishing an escrow account to ensure availability of funding for projects. The general conditions of contracts used by the SPC-E must be altered using its particular conditions to increase the payment duration time to contractors to facilitate the payment system used by the line ministry. This would reduce the claims on delayed payments and allow the ministry additional time to provide payments to the contractors, further reducing interest charges. The study illustrated the need to implement the recommendations made by the Uff and Thornhill (2010) commission of enquiry to curb the effects of delayed payments.

\section{Limitations}

The research paper was a study on the Special Purpose Company (SPC-E) and as a result only explored payment related issues for projects undertaken by the company during 2010 to 2019. Additionally, the data collected from the questionnaire only utilized contractors executing works 
for SPC-E during the study period. The findings and recommendations made would only be suitable to SPC-E. Further research into other special purpose companies will ensure a comprehensive approach to treat with the delayed payment culture developed over the past decade. Further analysis is also required into the bureaucratic process employed by the parent Ministry of the special purpose company to provide comprehensive improvement to the process.

\section{References}

[1] Abdul-Rahman, H., Kho, M., \& Wang, C. (2014). Journal of Professional Issues in Engineering Education Practice 140. Late Payment and Nonpayment Encountered by Contracting Firms in a Fast Developing Economy, 1-9.

[2] Ameer, N. (2005). Construction Industry Payment and Adjudication Act, Reducing Payment Default and Increasing Dispute Resolution Efficiency. International Forum on Construction Industry Payment Act and Adjudication, 13\&14 September 2005. Malaysia: Kuala Lumpur Convention Centre, Kuala Lumpur.

[3] Amoako, K. B. (2011, September). The effects of Delayed Payment on Cash Flow forecasting for Ghanaian Road Contractors. Kwame Nkrumah University of Science and Technology.

[4]Assaf, S. A., \& Al-Hejji, S. (2006). Causes of Delay in Large Construction Projects. International Journal of Project Management 24, 349-357.

[5] Charles-Ragoo, L. A. (2015). Fair Payment Security Strategy for the Trinidad and Tobago Construction Industry. St. Augustine, Trinidad: The University of the West Indies.

[6] Cheng, T., Soo, G., Kumaraswamy, M., \& Jin, W. (2009). Security of payment for Hong Kong Construction Industry Workable alternatives and suggestions. Building Journal Hong Kong China, 60-77. Retrieved from http://hdl.handle.net/10722/58571.

[7] Coggins, J., Elliott, R. F., \& Bell, M. (2010). Towards harmonization of construction industry payment legislation: a consideration of the success afforded by the East and West Coast models in Australia. Australasian Journal of Construction Economics and Building, 10 (3), 14-35.

[8] Creswell, J. W. (2003). Research Design: Qualitative, Quantitative and Mixed Methods Approaches. Nebraska: SAGE Publications.

[9] Elias, E. (2016, January 20). Trinidad and Tobago Guardian Newspaper. Retrieved November 15, 2018, from http://www.guardian.co.tt/business/emile-elias-pay-bonds6.2.350077.2e6458259b

[10] Kaka, A. (2001). The case for re-engineering contract payment mechanisms. 17th Annual ARCOM Conference (pp. 371 - 379). Association of Researchers in Construction Management, Vol 1.

[11] Mohamad, N., Suman, A. S., Harun, H., \& Hashim, H. (2018). Mitigating delay and nonpayment in the Malaysian construction industry. IOP Conference Series: Earth and Environmental Science. IOP Publishing.

[12] Mungroo, C.-A. (2016, July). Delayed Payments to Contractors Executing Government Funded Projects in Trinidad and Tobago: A Case Study of A Special Purpose Company. A Case Study of a Special Purpose Company. Trinidad and Tobago: University of the West Indies, St. Augustine.

[13] Odeh, A. M., \& Battaineh, H. T. (2002). Causes of construction delays: Traditional Contracts. International Journal of Project Management 20, 67-73.

[14]Pallant, J. (2013). SPSS SURVIVAL MANUAL, A step by step guide to data analysis using IBM SPSS 5th Edition. New York: McGraw-Hill Companies. 
[15] Ramdass, A. (2016, January 5). Trinidad Express. Retrieved November 15, 2018, from Contractors owed \$2 billion, hundreds laid off: https://www.trinidadexpress.com/news/local/contractors-owed-billion-hundreds-laidoff/article_340c4ff2-57fb-54d3-9847-7fa6791ad8fb.html

[16] Sherif, E., \& Kaka, A. (2003). Factors Influencing the Selection of Payment Systems in Construction Projects. 19th Annual ARCOM Conference (pp. 63-70). University of Brighton. Association of Researchers in Construction Management, Vol 1. 